\title{
Selective Advantage of a Spirillum sp. in a Carbon-limited Environment. Accumulation of Poly- $\beta$-hydroxybutyric Acid and Its Role in Starvation
}

\author{
By A. MATIN \\ Department of Medical Microbiology, Stanford University, \\ Stanford, California 94305, U.S.A. \\ C. VELDHUIS, V. STEGEMAN AND M. VEENHUIS \\ Department of Microbiology, State University of Groningen, Haren (Gr.), \\ The Netherlands
}

(Received 26 September 1978; revised 22 November 1978)

\begin{abstract}
A freshwater Spirillum sp., which apparently belongs to a niche of low nutritional status (Matin \& Veldkamp, 1978), accumulated poly- $\beta$-hydroxybutyric acid (PHB) during lactate-limited growth in continuous culture. The PHB content varied in a complex manner with the dilution rate $(D)$, but was greatest at the lowest $D$ value examined: about $18 \%$ (w/w) at $D=0.025 \mathrm{~h}^{-1}$. It is not known what mechanism accounted for PHB accumulation during carbon-limited growth. The resistance of cultures of Spirillum sp. to starvation after growth at various $D$ values was compared with that of a Pseudomonas sp. which appears to belong to relatively richer environments (Matin \& Veldkamp, 1978) and does not accumulate PHB. In Spirillum sp., resistance correlated directly with the PHB content of the culture subjected to starvation, whereas in Pseudomonas sp. it increased with RNA content. Further, after growth at $D=0.03$ to $0.05 \mathrm{~h}^{-1}$, the Spirillum sp. was much more resistant to starvation than was the Pseudomonas sp. Since the microflora of oligotrophic environments are probably often subjected to starvation conditions, PHB accumulation by Spirillum sp. during growth in such environments may assist survival. PHB in Spirillum sp. was rapidly degraded during starvation but it had no sparing effect on RNA degradation. It is not known how PHB enhanced resistance to starvation.
\end{abstract}

\section{INTRODUCTION}

We have previously described a Spirillum sp. and a Pseudomonas sp. which possess crossing substrate saturation curves. We found several physiological and morphological differences between these bacteria which are consistent with the different niches that they appear to occupy in nature: Spirillum sp. occupies those scarce in nutrients and Pseudomonas sp. occupies the richer ones capable of supporting rapid growth (Matin \& Veldkamp, 1978).

The studies described in this paper emanated from the observation of poly- $\beta$-hydroxybutyric acid (PHB)-like inclusions in electron micrographs of Spirillum sp., but not of Pseudomonas sp., grown under L-lactate limitation. Since PHB is believed to accumulate in bacteria primarily under conditions of carbon excess (Dawes, 1976; Dawes \& Senior, 1973) and because Spirillum sp. represents a bacterial type hitherto little studied (Matin \& Veldkamp, 1978; Harder et al., 1977), we investigated the influence of culture dilution rate $(D)$ on PHB accumulation. We also compared the ability of cells of Spirillum sp. and Pseudomonas sp., grown at different $D$ values, to withstand starvation stress. 


\section{METHODS}

Organisms and growth conditions. The freshwater Spirillum sp. DSM 1109 and Pseudomonas sp. DSM 1110, isolated in our laboratory (Matin \& Veldkamp, 1978), were used in these studies. These bacteria are in the Deutsche Sammlung von Mikroorganismen, Göttingen, West Germany. [The address previously given (Matin \& Veldkamp, 1978) erroneously specified München.] The medium and details of chemostat cultivation have been described previously (Matin et al., 1976; Matin \& Veldkamp, 1978). The chemostat had a working volume of $200 \mathrm{ml}$; the incubation temperature was $28^{\circ} \mathrm{C}$; L-lactate, which was the growth-limiting nutrient in most experiments, was supplied at $0.05 \%(\mathrm{w} / \mathrm{v})$. The steady-state cell density of the culture varied between 0.08 and $0.13 \mathrm{~g}$ dry wt $1^{-1}$ depending on the $D$ value. The $\mathrm{pH}$ was between $7 \cdot 0$ and $7 \cdot 3$. The $\mathrm{O}_{2}$ tension of the growing cultures was periodically monitored by an $\mathrm{O}_{2}$ electrode and was never below $80 \%$ air-saturation. To minimize evaporation of the culture fluid, the inflowing air was passed through a water column $(25 \times 8 \mathrm{~cm}) \mathrm{kept}$ at $28^{\circ} \mathrm{C}$. Bacteria were grown at a given $D$ value for at least five volume changes before they were considered to be in a steady-state.

Electron microscopy. To prepare thin-layer sections, cell pellets were fixed for $2 \mathrm{~h}$ at $4{ }^{\circ} \mathrm{C}$ in phosphatebuffered $2.5 \%(\mathrm{w} / \mathrm{v})$ glutaraldehyde, washed for $30 \mathrm{~min}$ in $0.1 \mathrm{M}$-phosphate buffer and post-fixed in phosphatebuffered $1 \%(\mathrm{w} / \mathrm{v}) \mathrm{OsO}_{4}$ for $1 \mathrm{~h}$. After washing with distilled water, the samples were stained for $30 \mathrm{~min}$ in uranyl acetate $[1 \%(\mathrm{w} / \mathrm{v})$ in double-distilled water]. The samples were dehydrated in a graded series of ethanol, embedded in Epon and, after sectioning with a diamond knife on an LKB ultramicrotome, were picked up on uncoated 300 mesh grids. For freeze-etching, cells were washed in $20 \%(\mathrm{v} / \mathrm{v})$ glycerol and the pellet was quickly frozen in liquid Freon and stored in liquid nitrogen. The specimens were freeze-fractured, etched for $30 \mathrm{~s}$, shadow-coated with platinum carbon and replicated with carbon in a freeze-etching unit (Balzers, Liechtenstein) by the method of Moor \& Mühlethaler (1963). Replicas were floated off on doubledistilled water, cleaned with $70 \%(w / v)$ chromic acid, rinsed with distilled water, treated with $20 \%(w / v)$ $\mathrm{NaOH}$ and finally washed in several changes of double-distilled water. The replicas were collected on bare 300 mesh copper grids. Specimens were examined in a Philips EM300 electron microscope at $80 \mathrm{kV}$.

Starvation procedure. After pure cultures of the bacteria had grown to a steady-state at various $D$ values, the medium flow into the culture vessel was stopped and the organisms were starved in the growth medium under otherwise unchanged conditions. Such a procedure probably bears a closer resemblance to starvation conditions in nature than the conventional method involving washing and resuspension of cells in fresh medium or buffer. At intervals during starvation, samples were removed; the level of the remaining culture fluid in the vessel was marked and any decrease in the fluid during further incubation was compensated for by adding sterile distilled water before taking the next sample. Viability was determined as described by Matin \& Veldkamp (1978).

$P H B$ and $R N A$ determination. Samples $(25 \mathrm{ml})$ removed from steady-state or starving cultures were centrifuged $\left(8300 \mathrm{~g} ; 20 \mathrm{~min} ; 4^{\circ} \mathrm{C}\right)$ and the pellets were taken up in distilled water. These suspensions were then suitably diluted and used in PHB and RNA determinations. PHB, RNA and dry weight were determined by the methods of Zevenhuizen \& Ebbink (1974), Munro \& Fleck (1966) and Matin \& Veldkamp (1978), respectively.

\section{RESULTS}

\section{PHB accumulation during L-lactate-limited growth}

Thin sections and freeze-etched preparations of Spirillum sp., grown at $D=0.05 \mathrm{~h}^{-1}$ under L-lactate limitation, showed the presence of inclusions (Fig. 1) which resembled PHB granules (Stevenson \& Socolofsky, 1966; Dunlop \& Robards, 1973). The mean number of these inclusions \pm S.E.M., based on a count of 100 thin sections, was $7 \cdot 59 \pm 0.29$ per cell at $D=0.05 \mathrm{~h}^{-1}$, and $5 \cdot 23 \pm 0 \cdot 19$ per cell at $D=0 \cdot 15 \mathrm{~h}^{-1}$, which suggested that the amount of PHB accumulated under these conditions might be a function of culture $D$. No granules were seen in the electron micrographs of Pseudomonas sp. grown at different $D$ values under L-lactate limitation.

Analysis of Spirillum sp. confirmed both the accumulation of PHB and the dependence of the amount accumulated on the culture $D$ value (Fig. 2). Cells grown at $D=0.15 \mathrm{~h}^{-1}$, contained the least amount of PHB, those grown at a higher or lower $D$ value contained higher amounts; the highest amount found (approx. $18 \%$ of dry wt) was in cells grown at the lowest $D$ value tested $\left(0.025 \mathrm{~h}^{-1}\right)$. Control experiments showed that L-lactate was the growthlimiting nutrient under these conditions, since an increase in its concentration in the inflow 

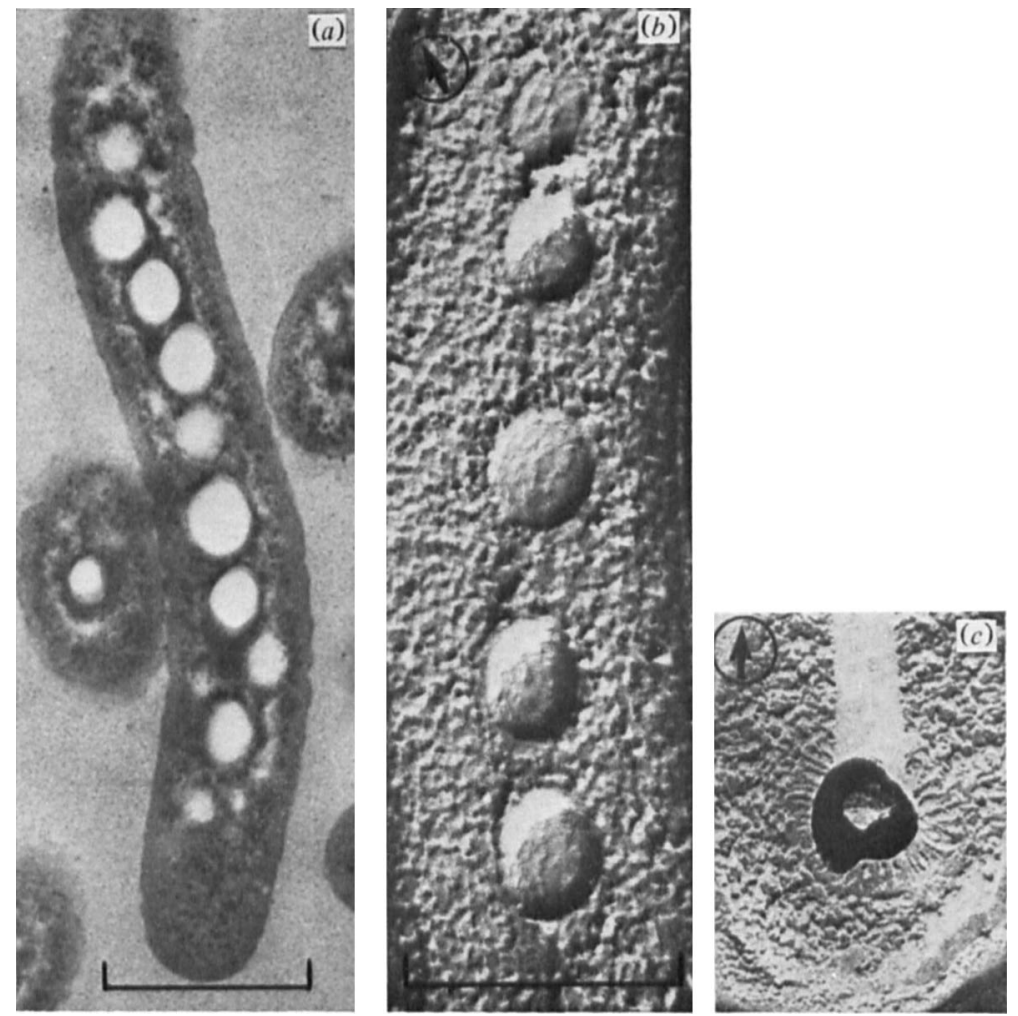

Fig. 1. Electron micrographs of Spirillum sp. grown at $D=0.05 \mathrm{~h}^{-1}$ under L-lactate limitation: (a) negatively stained longitudinal section; $(b)$ freeze-etched preparation; $(c)$ freeze-etched preparation showing the hole exposed by the removal of a PHB granule. Arrows (in $b$ and $c$ ) indicate the direction of shadow. Bar markers represent $3 \mu \mathrm{m}$.

medium from $0 \cdot 5$ to $4 \mathrm{~g} \mathrm{l}^{-1}$ caused a corresponding increase in the culture biomass. When Spirillum sp. was grown under ammonium limitation with L-lactate as the carbon source (by decreasing the concentration of $\mathrm{NH}_{4} \mathrm{Cl}$ in the medium to $0.2 \mathrm{~g}^{-1}$ and increasing that of L-lactate to $6 \mathrm{~g} \mathrm{l}^{-1}$ ), about $40 \%$ of the dry weight of cells grown at $D=0.03 \mathrm{~h}^{-1}$ was PHB; the amount of PHB formed under these conditions decreased as the culture $D$ was increased to $0.3 \mathrm{~h}^{-1}$ (results not shown), unlike the complex pattern of change observed under carbon limitation. Chemical analyses also failed to show the presence of PHB in Pseudomonas sp. grown under L-lactate or ammonium limitation at $D$ values ranging from 0.02 to $0.52 \mathrm{~h}^{-1}$.

\section{Starvation experiments}

After $30 \mathrm{~h}$ starvation, the residual viability of both organisms was a function of the $D$ value at which the culture had been grown prior to the onset of starvation (Fig. 3). In Pseudomonas sp., the survival increased linearly with the increasing $D$ value of the culture subjected to starvation, and correlated with the initial RNA content of the organisms (Fig. $4 b$ ), which also increased linearly [from 7 to $22 \%$ (w/w)] in the range of $D$ values examined. In contrast, the resistance to starvation of Spirillum sp. correlated with the initial PHB content of the culture (Fig. 4a). After growth at $D=0.03$ to $0.05 \mathrm{~h}^{-1}$, when the PHB content of Spirillum sp. was highest, approx. $60 \%$ of the cells of this organism were still viable after $30 \mathrm{~h}$ starvation, whereas virtually no survivors were found after this period of starvation in a culture which had been grown at $D=0.15 \mathrm{~h}^{-1}$ and hence contained the least amount of PHB (Figs 3 and $4 a$ ). It is evident that after growth at very low $D$ values, 


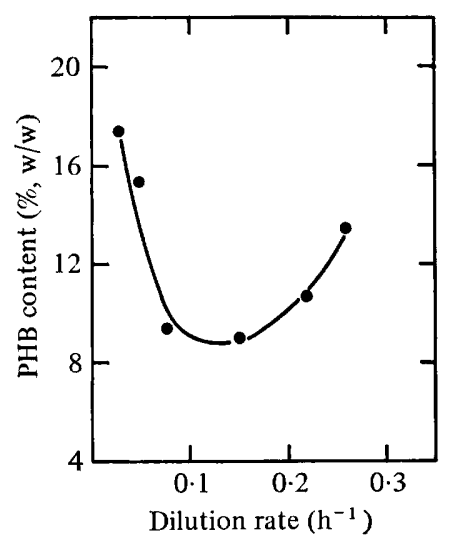

Fig. 2

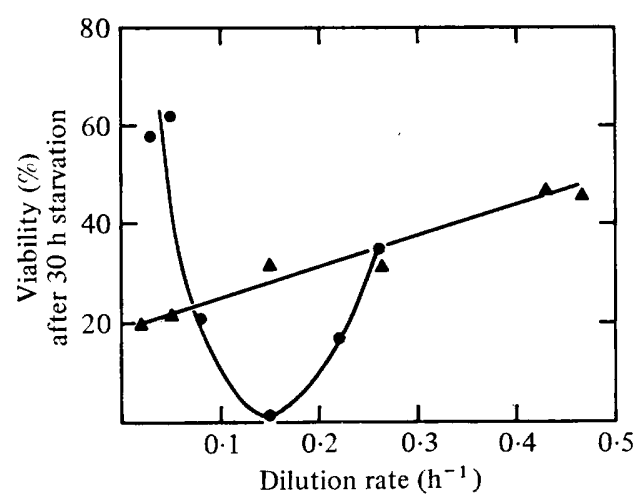

Fig. 3

Fig. 2. PHB content of Spirillum sp. grown at various dilution rates under L-lactate limitation.

Fig. 3. Viability of cultures of Spirillum sp. (O) and Pseudomonas sp. (A) after $30 \mathrm{~h}$ starvation as a function of the dilution rate at which cells had been grown before the onset of starvation. The growth-limiting nutrient was L-lactate.
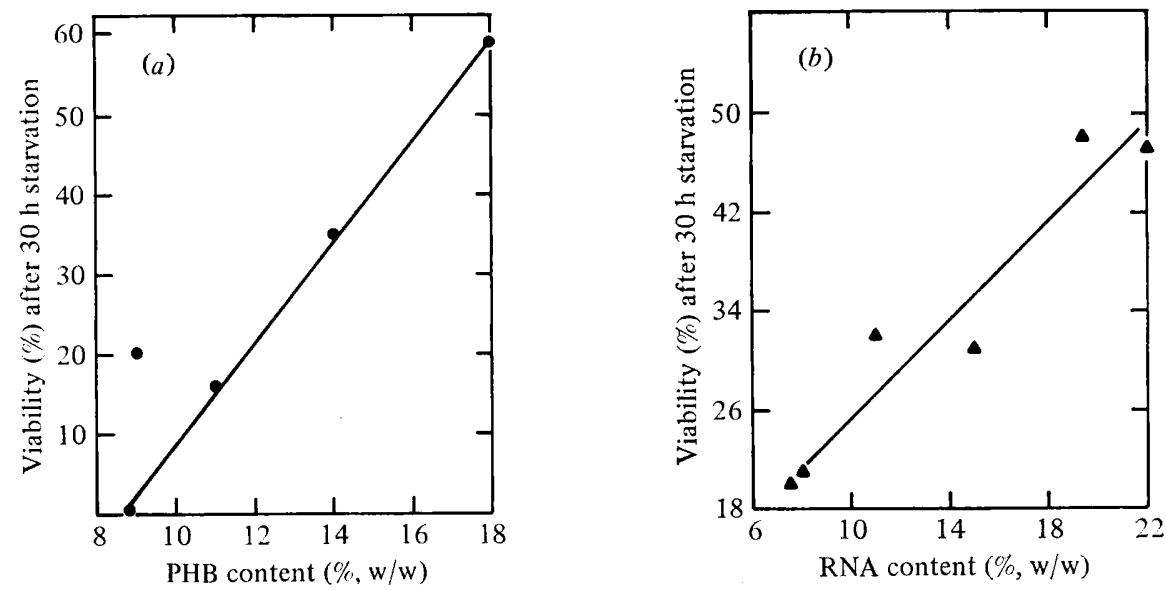

Fig. 4. Correlation between survival and (a) PHB content in Spirillum sp. and (b) RNA content in Pseudomonas sp.

i.e. very low ambient concentrations of L-lactate, the resistance to starvation of Spirillum sp. is much greater than that of Pseudomonas sp., but after growth at higher $D$ values the resistance of Pseudomonas sp. is either equal or greater.

Since PHB degradation during starvation delays or slows down RNA breakdown in some bacteria (Hippe, 1967), we compared the rate of RNA breakdown in the two bacteria during starvation after growth at various $D$ values. PHB was rapidly degraded by the starving cells of Spirillum sp. regardless of the $D$ value at which they had been grown and hence of the amount of PHB they contained at the start of starvation (Fig. 5); nevertheless, the rate of RNA breakdown was higher in Spirillum sp. than in Pseudomonas sp. after growth at similar $D$ values. That the possession of PHB had no sparing effect on RNA breakdown in Spirillum sp. is further indicated by the absence of an inverse correlation between the rate of RNA degradation in the starving cells of this bacterium and their initial PHB content; for instance, organisms grown at $D=0.26 \mathrm{~h}^{-1}$ contained more PHB than those grown at $D=0.08 \mathrm{~h}^{-1}$, and yet the former degraded their RNA at a faster rate. It is not known why an initial increase in RNA was observed in starving cells of both the organisms after growth 

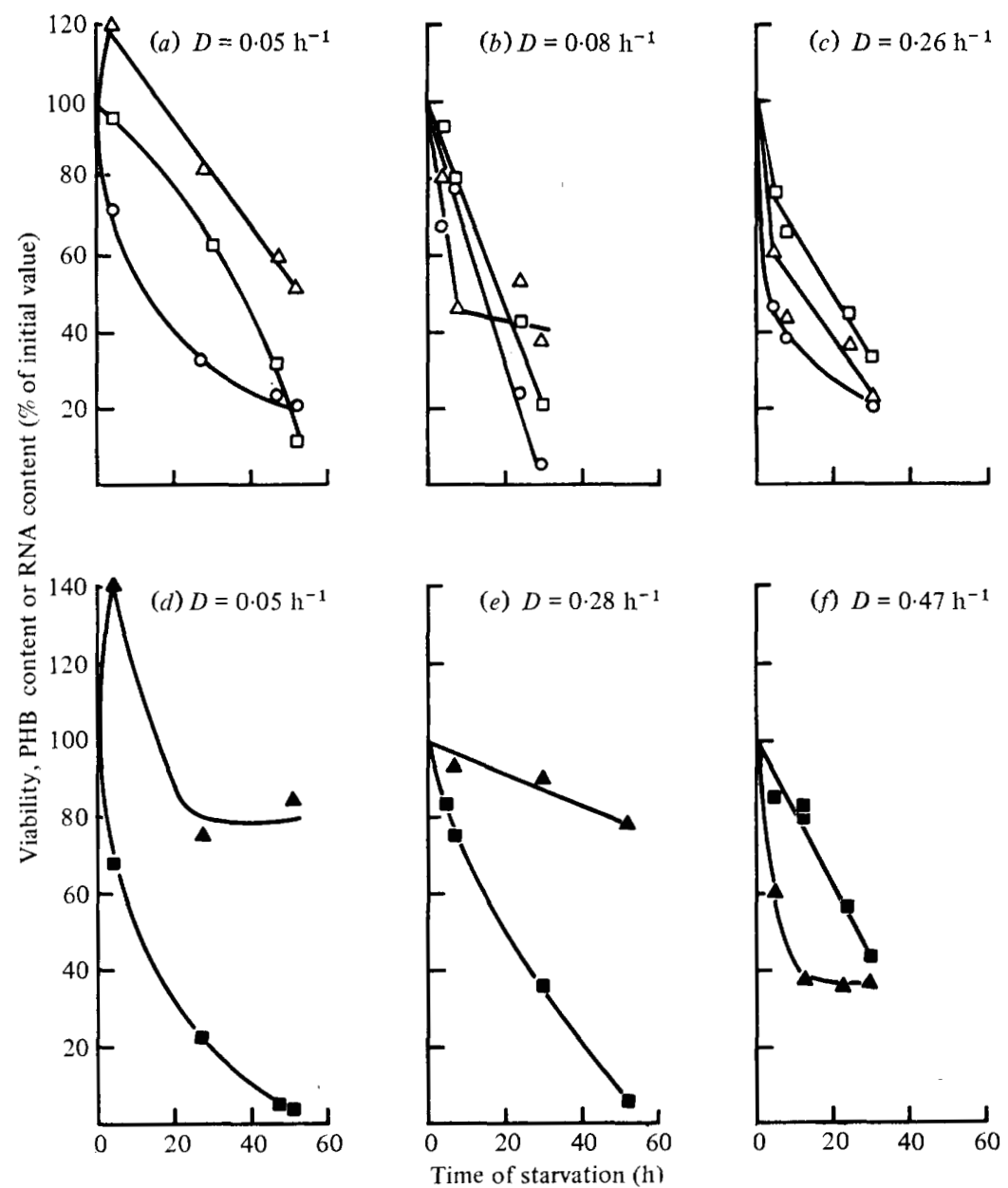

Fig. 5. Viability $(\square, \square)$, PHB $(O)$ and RNA $(\Delta, \Delta)$ contents of organisms during starvation. The organisms had been grown to steady-state at the specified dilution rates prior to the onset of starvation. $(a, b, c)$ Spirillum sp.: the steady-state RNA contents $(\mathrm{w} / \mathrm{w})$ before starvation were $(a)$ $7.2 \%$, (b) $8.2 \%$ and $(c) 13 \%$; see Fig. 2 for the PHB content of cells at the same dilution rates. $(d, e, f)$ Pseudomonas sp.: the steady-state RNA contents (w/w) before starvation were $(d) 8 \%$, (e) $15 \%$ and $(f) 22 \%$.

at $D=0.05 \mathrm{~h}^{-1}$. In general, the rate of RNA breakdown in the bacteria during starvation increased with increasing $D$ value of the culture subjected to starvation.

\section{DISCUSSION}

The capacity of Spirillum sp. to accumulate PHB during carbon- (and energy-)limited growth is unusual since only two other instances of such accumulation have previously been reported: Bacillus megaterium (Wilkinson \& Munro, 1967) and Azotobacter beijerinckii (Senior et al., 1972), which formed up to 13 and $3 \%$ (w/w) PHB, respectively, during glucose-limited growth. As with Spirillum sp., the PHB content of both these bacteria was markedly influenced by their growth rate.

If bacteria in nature are often exposed to starvation for carbon (and energy), as is likely to be the case, then the advantage of saving a critical resource in times of relative plenty is of evident survival value. That accumulation of PHB enhanced resistance of Spirillum sp. to 
carbon starvation is strongly suggested by the correlation between the PHB content of the different populations of this bacterium and their resistance to this stress; that such accumulation might be of selective advantage is indicated by the fact that after growth under conditions leading to a relatively high PHB content, the resistance of Spirillum sp. to starvation was significantly greater than that of Pseudomonas sp. (which does not accumulate this polymer). The ability of Spirillum sp. to synthesize PHB reserves during growth at limiting and very low concentrations of a carbon compound would therefore appear to be another adaptation, in addition to those previously reported, by this bacterium in response to its natural niche of an oligotrophic environment (Matin \& Veldkamp, 1978). The advantage of Spirillum sp. during starvation obtains only subsequent to growth in this sort of environment; after growth in richer environments, the resistance to starvation of Pseudomonas sp. was equal to or greater than that of Spirillum sp.

Synthesis of $\mathrm{PHB}$ is believed to be triggered by conditions which tend to raise the internal $\mathrm{NAD}(\mathrm{P}) \mathrm{H}$ concentrations (Dawes \& Senior, 1973), such as growth under $\mathrm{NH}_{4}{ }^{+}, \mathrm{K}^{+}$or $\mathrm{O}_{2}$ limitation; the PHB synthesized probably serves as an electron sink for the excess reducing power (Senior et al., 1972). However, the regulatory mechanism which led to PHB synthesis in Spirillum sp. under carbon-limited and highly aerobic conditions must be different, since under these conditions reducing equivalents are likely to be limiting rather than be in excess. Similarly, the mechanism of dependence of PHB content on culture growth rate is not known, though growth rate profoundly influences the enzymic and co-factor composition of these bacteria (Matin et al., 1976; Matin \& Gottschal, 1976).

Spirillum sp. containing relatively low amounts of PHB was more vulnerable to starvation than Pseudomonas sp.: for instance, after growth at $D=0.15 \mathrm{~h}^{-1}$ [PHB content of Spirillum sp.: $9 \%(\mathrm{w} / \mathrm{w})], 30 \mathrm{~h}$ starvation led to a virtually complete loss of viability in the culture of Spirillum sp., but left about $30 \%$ survivors in that of Pseudomonas sp. Since the RNA contents of the two organisms at this $D$ value were similar [about $11 \%(\mathrm{w} / \mathrm{w})$ ] the results suggest that the main line of defence of Spirillum sp. to starvation is the accumulated PHB. The mechanism whereby PHB may enhance survival of Spirillum sp. is unknown. It is evident that degradation of PHB during starvation did not spare cellular RNA in this bacterium but it is conceivable that this degradation is required to balance some physiological parameter, such as the energy charge (Montague \& Dawes, 1974), at a value necessary for survival.

Work reported in this paper is based in part on the Master's theses of C. Veldhuis and V. Stegeman.

\section{REFERENCES}

Dawes, E. A. (1976). Endogenous metabolism and the survival of starved prokaryotes. Symposia of Society for General Microbiology 26, 19-53.

Dawes, E. A. \& SENIOR, P. J. (1973). The role and regulation of energy reserve polymers in microorganisms. Advances in Microbial Physiology 10, 135-266.

Dunlop, W. F. \& Robards, A. W. (1973). Ultrastructural study of poly- $\beta$-hydroxybutyrate granules from Bacillus cereus. Journal of Bacteriology 114, 1271-1280.

Harder, W., Kuenen, J. G. \& Matin, A. (1977). Microbial selection in continuous culture. Journal of Applied Bacteriology 43, 1-24.

HIPPE, H. (1967). Abbau und Wiederverwertung von Poly- $\beta$-hydroxybuttersäure durch Hydrogenomonas H16. Archiv für Mikrobiologie 56, 248-277.

Matin, A. \& GotTschal, J. C. (1976). Influence of dilution rate on NAD(P) and NAD(P)H concen- trations and ratios in a Pseudomonas sp. grown in continuous culture. Journal of General Microbio$\log y$ 94, 333-341.

Matin, A. \& VeldKamp, H. (1978). Physiological basis of the selective advantage of a Spirillum sp. in a carbon-limited environment. Journal of General Microbiology 105, 187-197.

Matin, A., Grootjans, A. \& Hogenhuis, H. (1976). Influence of dilution rate on enzymes of intermediary metabolism in two freshwater bacteria grown in continuous culture. Journal of General Microbiology 94, 323-332.

Montague, M. D. \& Dawes, E. A. (1974). The survival of Peptococcus prévotii in relation to the adenylate energy charge. Journal of General Microbiology 80, 291-299.

MooR, H. \& MüHLETHALER, K. (1963). Fine structure in frozen-etched yeast cells. Journal of Cell Biology 17, 609-628. 
Munro, H. N. \& FleCK, A. (1966). The determination of nucleic acids. Methods of Biochemical Analysis 14, 113-117.

Senior, P. J., Beech, G. A., Ritchie, G. A. F. \& DAwEs, E. A. (1972). The role of oxygen limitation in the formation of poly- $\beta$-hydroxybutyrate during batch and continuous culture of Azotobacter beijerinckii. Biochemical Journal 128, 1193 1201.

Stevenson, L. H. \& Socolofsky, M. D. (1966) Cyst formation and poly- $\beta$-hydroxybutyric acid accumulation in Azotobacter. Journal of Bacterio$\log y$ 91, 304-310.
Wilkinson, J. F. \& Munro, A. S. (1967). The influence of growth limiting conditions on the synthesis of possible carbon and energy storage polymers in Bacillus megaterium. In Microbial Physiology and Continuous Culture, pp. 173-185. Edited by E. O. Powell, C. G. T. Evans, R. E. Strange \& D. W. Tempest. London: H.M.S.O.

Zevenhuizen, L. P. T. M. \& EbbinK, A. G. (1974). Interrelations between glycogen, poly- $\beta$-hydroxybutyric acid and lipids during accumulation and subsequent utilization in a Pseudomonas. Antonie van Leeuwenhoek 40, 103-120. 